\title{
NEW MATRIX FORMULAS FOR LAGUERRE MATRIX POLYNOMIALS
}

\author{
BAYRAM ÇEKIM AND ABDUllah Altin
}

\begin{abstract}
In this paper, we obtain some properties for Laguerre matrix polynomials. The relations between Laguerre and Jacobi matrix polynomials in this study are indicated. We also derive multilinear and multilateral generating matrix functions for Laguerre matrix polynomials.
\end{abstract}

Mathematics subject classification (2010): 33C45, 15A60.

Keywords and phrases: Laguerre matrix polynomials, Jacobi matrix polynomials, generating matrix function, beta matrix function.

\section{REFERENCES}

[1] E. DEFEZ, L. JóDAR AND A. LAW, Jacobi matrix differential equation, polynomial solutions and their properties, Computers and Mathematics with Applications 48 (2004) 789-803.

[2] E. DEFEZ AND L. JóDAR, Some applications of the Hermite matrix polynomials series expansions, J. Comp. Appl. Math. 99 (1998) 105-117.

[3] L. JódAR AND J. C. CoRTÉs, On the hypergeometric matrix function, J. Comput. Appl. Math. 99 (1998) 205-217.

[4] L. Jódar And J. C. Cortés, Some properties of Gamma and Beta matrix functions, Appl. Math. Lett. Vol. 11 (1) (1998) 89-93.

[5] L. JóDAR, E. DEFEZ AND E. PONSODA, Orthogonal matrix polynomials with respect to linear matrix moment functionals: Theory and applications, J. Approx. Theory Appl., 12 (1) (1996) 96-115.

[6] L. JÓDAR, R. COMPANY AND E. NAVARRO, Laguerre matrix polynomials and system of secondorder differential equations, Appl. Num. Math. 15 (1994) 53-63.

[7] N. Dunford AND J. Schwartz, Linear Operators, Vol. I, Interscience, New York, 1957.

[8] RAed S. BATAHAN, A new extension of Hermite matrix polynomials and its applications, Linear Algebra and its Applications 419 (2006) 82-92. 